\title{
Thorough documentation of the accidental aspiration and ingestion of foreign objects during dental procedure is necessary: review and analysis of 617 cases
}

Rui Hou ${ }^{1 *}$, Hongzhi Zhou ${ }^{1}$, Kaijin Hu${ }^{1}$, Yuxiang Ding ${ }^{1}$, Xia Yang ${ }^{1}$, Guangjie Xu' ${ }^{1}$, Peng Xue ${ }^{1}$, Chun Shan ${ }^{1}$, Sen $\mathrm{Jia}^{1}$ and Yuanyuan $\mathrm{Ma}^{2}$

\begin{abstract}
Objectives: To review the cases of accidental aspiration and ingestion of foreign objects during dental procedure, and to emphasize the importance of thorough documentation of the accidents.

Methods: A comprehensive search on (dental procedure/treatment/practice), (aspiration/inhalation), and (ingestion/ swallow) was performed for all years before 1st October 2014 available. The statistic analysis was made on the variables including journals and reported year, patients' age, gender, general conditions, dental procedure and location for procedure, foreign objects, site of involvement, possible causes, anesthesia during procedure and treatment, symptoms, treatment time and treatment modality, follow-up, and so on.

Results: A total of 617 cases reported by 45 articles from 37 kinds of journals were included and analyzed. Most reports made detailed record. While some important variables were recorded incompletely, including patient's general conditions, location for procedure, clinical experience of the involving dentists, tooth position of procedure, possible causes, and anesthesia during procedure and treatment for the accident.
\end{abstract}

Conclusions: Aspiration and ingestion of foreign objects are rare and risky complication during dental procedure. Each accident should have thorough documentation so as to provide enough information for the treatment and prevention.

Keywords: Aspiration, Ingestion, Foreign objects, Dental procedure, Documentation

\section{Background}

Aspiration and ingestion of foreign objects are potential complications that can occur during dental procedure, such as root canal therapy, implantation, extraction, and even routine examination. The foreign object included endodontic instruments, implant components, burs, posts, teeth, orthodontic brackets, restorations and even dental mirror and irrigation needle [1-5].

The incidences of aspiration and ingestion in dental procedure have been reported by many articles and

\footnotetext{
* Correspondence: denthr@sina.com; hourui@fmmu.edu.cn

${ }^{1}$ State Key Laboratory of Military Stomatology \& National Clinical Research Center for Oral Diseases \& Shaanxi Clinical Research Center for Oral Diseases, Department of Oral Surgery, School of Stomatology, the Fourth Military Medical University, Xi'an City, Shaanxi Province 710032, China

Full list of author information is available at the end of the article
}

reviews. As early as 1971, Grossman [6] determined that $87 \%$ of foreign bodies entered the alimentary tract, whereas $13 \%$ aspirated into the respiratory tract. Susini G et al. [7] reported that the incidences of aspiration and ingestion in root canal treatment were 0.001 per 100000 and 0.12 per 100000 , respectively. From different dental college hospitals in Japan, the ingestion of foreign objects was reported 0.0041 and $0.0044 \%[8,9]$. Moreover, the occurrence (cases/dentists) per year was 0.018 , which was very close to the figure of 0.021 reported from two French insurance companies representing 24,651 French general dental practitioners over an 11-year period [7].

The literature also showed that although $90 \%$ of ingested foreign objects could pass through the 
gastrointestinal tract uneventfully, there are roughly $10 \%$ require endoscopic removal, while still $1 \%$ will ever require operation $[6,8,10,11]$. Although bronchoscopy has been reported $99 \%$ effective on retrieve the aspirated foreign objects, the complication rate is between 2.4 and $5 \%$ [12].

Many factors are reported related to the aspiration and ingestion. For example, patients' medical and mental condition, use of local anesthesia or intravenous sedation, difficulty of access, compromised direct view, and so on [2-5]. However, these factors are still in controversy. There were also some important variables recorded incompletely from the literature, such as tooth position of procedure, clinical experience of the involving dentists, and anesthesia during procedure. In addition, many articles even did not report the necessary information of the cases. Moreover, there were hardly any review on making comprehensive record and discussion of accidental aspirated and ingested cases.

Therefore, it has necessity to strengthen the thorough documentation so as to arouse the dental personnel's attention, and further to facilitate analysis of the reasons, accumulation of the experience and lessons, and summary of the prevention and treatment measures on accidental aspiration and ingestion.

\section{Methods}

\section{Literature search}

An extensive literature search was conducted in four electronic databases: PubMed, Cochrane Library, ScienceDirect, and Embase databases. The following filters were used in the search strategy: date (1970/01/01 to 2014/10/01) and species (humans) filters in PubMed, and only date (1970-2014) filter for the remaining three databases. The reference lists of all relevant articles were also screened manually to identify further potentially relevant articles.

The inclusion criteria were as follows: (1) case reports, case series, review articles and retrospective studies; (2) studies reporting the accidental aspiration and ingestion of foreign objects during the dental procedure, dental treatment, and dental practice. (3) studies reporting at least the following information: dental procedure and foreign objects, site of involvement and symptoms, treatment modality and follow-up. (4) studies published in English.

The exclusion criteria were as follows: (1) studies contained limited data including conference abstracts and letters to journal editors, and opinion articles; (2) studies reporting the accidents happening in time other than dental treatment; (3) studies only reporting the prevention and treatment measure of aspiration or ingestion without cases.

Two reviewers independently judged the study eligibility, and any disagreement was resolved by consensus.
The descriptive variables were extracted and collected thoroughly, including journals and reported year, patients' age, gender, general conditions, dental procedure, location for procedure, clinical experience of the involving dentists, tooth position of procedure, possible causes, foreign objects, site of involvement, symptoms, treatment time and treatment modality, anesthesia during procedure and treatment for the accident, and follow-up.

\section{Statistical analysis}

SPSS version 13.0 for Windows was used for statistical analysis. The descriptive statistics were made on all the descriptive variables from the selected articles.

\section{Results}

A total of 617 cases reported were included and analyzed in this review. Most cases were recorded in detail, while some important variables were incomplete. The statistical analysis results were listed below based on the different descriptive variables.

\section{Variables recorded in detail Journals and reported year}

There were altogether 45 articles published by 37 kinds of journals on aspiration and ingestion during dental procedure. Table 1 showed the analysis on cases number from the articles. Figure 1 showed cases number and their reported year (except four reviews).

More than $80 \%$ of the articles (37/45) were from dental journals. Among them, 19 articles were from comprehensive dentistry $[8,9,11,13-28], 6$ from oral sugery [10, 29-33], 6 from endodontics [7, 34-37], 3 from prosthodontics [1, 38, 39], 2 from implantation $[4,40]$ and 2 from orthodontics [41, 42]. The others 8 were from the fields of gastroenterology [43], respiration [44], laryngology [45], pediatrics [46] and comprehensive medicine [4, 47-49].

\section{Age and gender}

Figure 2 showed aspiration and ingestion were more seen in patients at 60-79 years old and 10-19 years old, respectively. Of all the 49 cases in case reports, the

Table 1 Analysis on cases number from the articles (case number)

\begin{tabular}{lllll}
\hline & Year & Aspiration & Ingestion & Total \\
\hline Review from France [7] & $1994-2004$ & 44 & 464 & 508 \\
Review from Japan [8] & $2008-2009$ & 0 & 11 & 11 \\
Review from Japan [9] & $2006-2010$ & 0 & 23 & 23 \\
Review from USA [13] & $1992-2002$ & 1 & 25 & 26 \\
Case reports & $1971-2014$ & 20 & 29 & 49 \\
Total number & & 65 & 552 & 617 \\
\hline
\end{tabular}




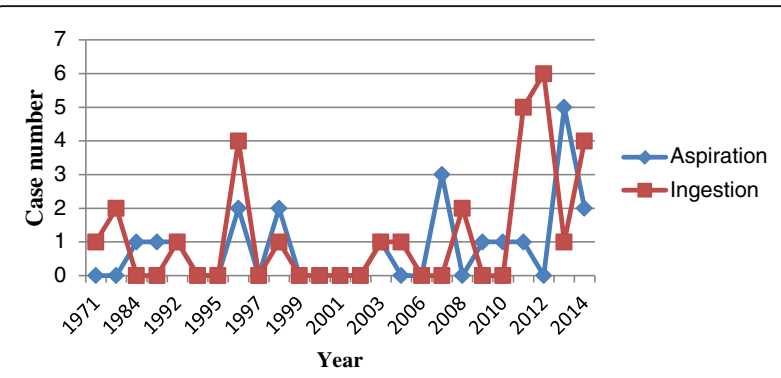

Fig. 1 Analysis on cases number and its happened year. Showed cases number and their reported year (except four reviews)

aspiration and ingestion case number were 18 and 15 in male, 2 and 12 in female. There were even 2 cases did not specify gender [27].

\section{Dental procedure and foreign objects}

Aspiration happened more during implantation [10, 19, $30,33,40,46]$, prosthodontics $[13,14,20,28]$, and restorative dentistry $[11,14,22,28,45]$. Ingestion happened more during prosthodontics $[9,13,29,39]$ and RCT [9, 11, 13, 16-19, 24, 27, 34, 35, 37, 43, 49] (Fig. 3). Table 2 listed the top five kinds of foreign objects that were aspirated and ingested in the case reports and reviews.

\section{Site of involvement and symptoms}

For the aspirated cases, 7 cases were found foreign objects at right bronchus $[10,11,14,22,30,31,33]$, 6 at left bronchus $[15,19,36,44,45,48], 5$ at right lung $[13,14,20,28,40], 1$ at lung without description on left or right [28], and the other one at the piriform fossa [10]. For the ingested cases, 24 cases were found at stomach $[4,9,11,16,18,21,27,29,32,35,37,42,47,49], 10$ at intestine $[9,27,46], 11$ at stomach and intestine [8], and esophagus (5 cases) $[9,23,25]$.

Of all the 49 cases, 9 aspirated cases had symptom, including 7 cough $[10,15,19,22,31,36,40], 1$ pain [20], 1 gag [28]. Four ingested cases had symptoms, including 3 pain [11, 43, 46] and 1 cough [34]. All the reviews had no description on the symptoms.

\section{Treatment time, modality and follow-up}

Table 3 showed two thirds of the aspirated cases (13/20) got immediate treatment $[10,11,14,15,19,22,30,31$, $33,40,44,45,48]$, while nearly $40 \%$ of ingested cases $(12 / 29)$ got observation with foreign objects excreted 2 days to 2 weeks later $[18,21,24,27,29,34,35,37,39$, 41, 49]. Among the 34 ingested cases in reviews from Japan $[8,9]$, only 3 cases retrieved by endoscopic procedure immediately, the others passed through the gastrointestinal tract in a 10-day period.

Of all the 20 aspirated cases, 15 cases had the foreign objects successfully retrieved by bronchoscopy (7 flexible $[10,14,28,40,44,45], 5$ rigid $[22,30,31,33,48]$ and 3 without description $[15,19,36])$ and 1 case by laryngoscopy [10]. Three cases failed to retrieve the object after bronchoscopy, including 1 observed with excretion until 6 months later [14], 1 had lung wedge resection 3 days later [14], and 1 got recall every month but without final result reported [36]. The last one case got the lobectomy of right lobe when the dental impressions were found aspirated 1 year later [20].

Of all the 29 ingested cases, 12 got foreign bodies excretion, including 10 with observation before [21, 24, $27,29,34,35,39,41,49]$ and 2 with immediate endoscopy failed before [18, 37], 15 had the objects retrieved by endoscopy ( 7 immediate [11, 17, 23, 25, 32, 34, 42], 8 several-day later $[1,4,11,16,29,43,47])$, and the other 2 had laparatomy [38] and colostomy [46], respectively.

For follow-up, only one case reported happening acute airway obstruction after bronchoscopy [33]. The symptom finally disappeared after suitable treatment. There were no adverse events or description to the other cases.

\section{Variables recorded incompletely General conditions}

There were only 12 cases (12/617) reporting patients with general disease, including 6 cases of cerebrovascular disease [9, 19], 2 cases of tumor excision [33, 38], 1 case of attention deficit hyperactivity disorder [15], 1 case of low intelligence quotient [17], 1 case of dental retardation [21] and 1 case of cleft palate [41].

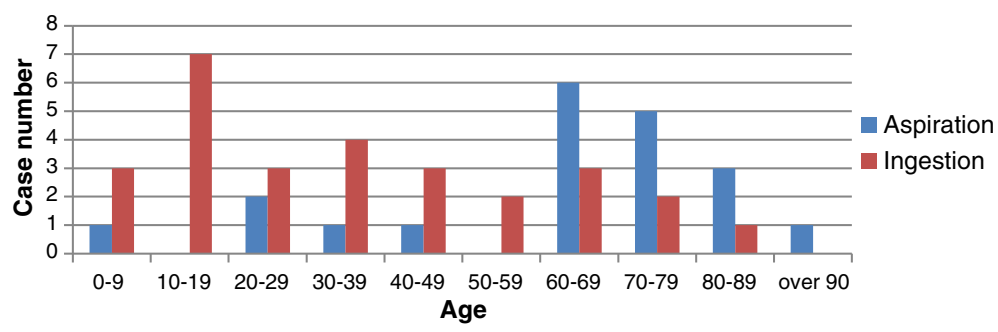

Fig. 2 Analysis on the patient's age of the cases. Showed that aspiration and ingestion were more seen in patients at 60-79 years old and 10-19 years old, respectively 


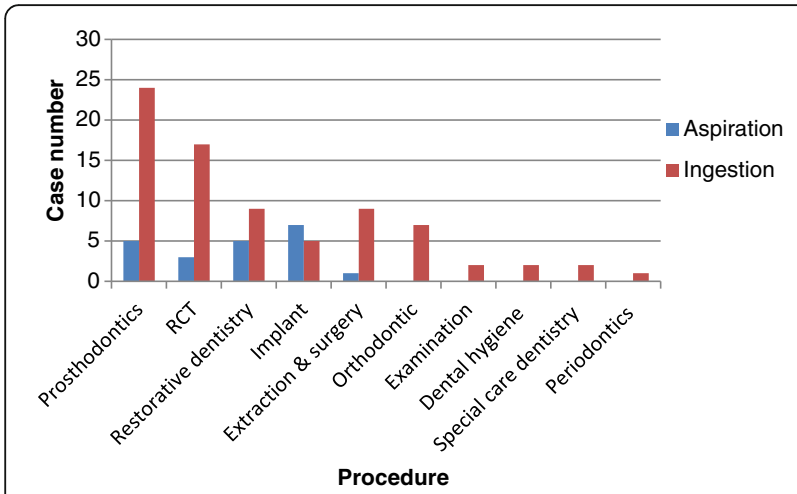

Fig. 3 Analysis on the dental procedure of the cases. Showed that aspiration happened more during implantation, prosthodontics, and restorative dentistry. Ingestion happened more during prosthodontics and $\mathrm{RCT}$

\section{Location for procedure and clinical experience of the involving dentists}

In the case reports, there were 14 cases happened at private clinic/hospital $[10,15,16,19,22,25,30,34,36,37$, 40, 41], 17 cases happened at dental clinic or department in hospital or college hospital $[1,4,14,17,18,21,23,24$, $27,32,33,35,38,39,42,49]$; the other 18 cases had no description. In four reviews, there were 60 cases from dental clinics of university hospital [8, 9, 13], the other 508 cases were from general dental clinic [7].

Only two reviews from Japan made detailed analysis on clinical experience of the involving dentists $[8,9]$. Both of them thought the accidental ingestion occurred more frequently when procedures were being conducted by practitioners with less experience ( 5 to 10 years [8], less than 5 years [9]).

\section{Tooth position of procedure and causes}

In the case reports, only 16 cases $[10,15-17,23,24,27$, $28,31,34,35,49$ ] were recorded detailed tooth position of procedure. Two reviews reported the ingestion occurred more frequently during treatment of lower molars $[8,9]$. The other two reviews had no description $[7,13]$.

In the case reports, only 14 cases mentioned the causes, including 6 cases of closing mouth and moving head $[15,17,25,34,41,46], 3$ of discomfort and uncooperative [18, 23, 33], 2 of gagging reflex [24, 31], 2 of instrument fatigue [21, 27], and 1 of no floss tie [11]. All the reviews had no description on the causes.

\section{Anesthesia during procedure and treatment for the accident} During the procedure, only 5 cases received local anesthesia (3 aspirated [1, 23, 43], 2 ingested [31, 33]), 2 cases received sedation (1 aspirated [10], 1 ingested [32]). The other 43 cases and 4 reviews did not receive any anesthesia nor had the record.

During the treatment for aspiration, there were 10 cases received general anesthesia $[14,15,19,20,30,31$, $33,36,48], 3$ cases received sedation [10, 40], 2 cases received local anesthesia [22, 44], and the other 5 cases had no record $[11,14,28,45]$. During the treatment for ingestion, there were 7 cases received general anesthesia $[17,23,25,29,39,46,47], 2$ cases received sedation [32, 42], the other 20 cases did not receive any anesthesia nor had the record.

\section{Discussion}

Aspiration or ingestion of foreign objects including instruments, materials or even tooth is a relatively uncommon risk during dental procedures [14]. Yet, it is reported to be the second most common reason for foreign body aspiration in the lung [13]. Actually, the accidents could happen during various dental procedures due to some factors and associated with certain incidence, suggesting the importance of patient's safety and instituting precautions and countermeasures at all times.

However, most literature only reported one or several cases with limited information on the description of the accidents. There were hardly any review on making comprehensive record and discussion of accidental cases.

Therefore, thorough documentation of the accident is stressed in this study so as to arouse the dental personnel's attention, and further to facilitate analysis of the literature, and summarize the prevention and treatment measures on accidental aspiration and ingestion.

In this article, a total of 617 cases reported by 45 articles were reviewed. The statistical analysis was based on

Table 2 The top five kinds of foreign objects aspirated and ingested (case number)

\begin{tabular}{|c|c|c|c|c|c|}
\hline \multirow[t]{2}{*}{ Foreign objects } & \multicolumn{2}{|c|}{ Case reports } & \multirow[t]{2}{*}{ Foreign objects } & \multicolumn{2}{|l|}{ Reviews } \\
\hline & Aspiration & Ingestion & & Aspiration & Ingestion \\
\hline Endodontic file (\& reamer) & 3 & 11 & Prosthesis \& crown & 32 & 171 \\
\hline Screwdriver (\& screw) & 6 & 6 & Bur & 0 & 126 \\
\hline Crown \& bridge & 3 & 1 & Endodontic file & 1 & 57 \\
\hline Bur \& drill & 3 & 0 & Inlay core & 7 & 49 \\
\hline Rubber dam clamp & 0 & 2 & Broach & 0 & 27 \\
\hline
\end{tabular}


Table 3 Treatment time of the aspirated and ingested cases (number)

\begin{tabular}{|c|c|c|c|c|c|c|c|c|c|c|c|c|c|}
\hline & Immediate & $2 d$ & $3 d$ & $4 d$ & $5 d$ & $7 d$ & $2 w$ & $5 w$ & $2 \mathrm{~m}$ & $1 y$ & $3 y$ & $7 y$ & Total \\
\hline Aspiration & 13 & 2 & 1 & 1 & & & & 1 & & 1 & 1 & & 20 \\
\hline Ingestion (treatment) & 7 & 1 & 1 & & 1 & 3 & 2 & & 1 & & & 1 & 17 \\
\hline Ingestion (observation and excretion) & & 2 & 5 & 1 & 2 & 1 & 1 & & & & & & 12 \\
\hline
\end{tabular}

the different descriptive variables. Most reports made detailed records on patients' age, gender, dental procedure and foreign objects, site of involvement and symptoms, treatment time and modality, and follow-up.

Figures and tables showed there were more accidental cases happened in recent years. Aspirated and ingested cases were more seen in older patients and younger patients, respectively. Male patients suffered more cases than female patients. And the cases were more seen in the fine, cumbersome, and time-consuming procedure. In addition, any kinds of foreign objects could be aspirated or ingested regardless of the shape, size, and even length.

In aspirated cases, foreign objects were found more at right bronchus or lung because the connection from the trachea to the right bronchus is a less marked angle; moreover, the right bronchus has a greater diameter than the left $[4,5,50]$. In ingestion cases, the site of involvement was probably related with the time after the accident. If the checking time is short after the ingestion, the object may be in the stomach; otherwise it will be in the intestine. Since half of the aspirated patients and more than $90 \%$ of the ingested patients had no symptom, it suggested to us that once the instruments, material and even tooth could not be found during procedure, possible aspiration and ingestion might be detected.

From the results, it suggests that once aspiration is confirmed, immediate treatment should be done, since the majority of the cases need endoscopy or even surgery. However, once ingestion is confirmed, observation could be performed until the foreign object excreted. If there is no possible of excretion [18], endoscopy should be chosen. The follow-up also suggested that the treatment was suitable and the complications were under control. The prognosis was pretty good.

However, there were still some important variables recorded incompletely. It showed that only 12 cases reported patient's general conditions. The finding contradicts the widely held belief that patients with a neuromuscular disease or a physical handicap are at high risk of aspirating or ingesting dental foreign objects.

The results also showed that even 18 cases did not report the location of the accident, that only a small number of cases recorded detailed tooth position, and that only a few cases recorded the clinical experience and occupations of the involving dentists though it was found even lecturer and assistant professor with more than 20 years' experience can make mistakes in this respect [9].

As for the causes, it has been reported $[4,5,14,51]$ that psychotic individuals, alcoholics, mentally disabled individuals, patients who are nervous or restless, and patients who wear dentures ascribed to reduced tactile sensitivity of the palatal mucosa are at high risk of inhaling and swallowing foreign objects, but there were only few records in the dental procedure literature we studied $[15,21]$. On the contrary, other possible factors were not recorded in detail, including supine positioning, excessive gag reflex or unexpected patient movement, inadequate lighting, ineffective assistants, instrument fatigue, difficulty of access (posterior areas), and compromised direct view.

In addition, local anesthesia and intravenous sedation had been suggested as the possible reason, since sedation decreases the protective swallowing and coughing reflexes $[14,15]$. However, the reason was in controversy since most cases during the procedure in the study did not receive any anesthesia nor had the record. The anesthesia during the treatment for the accidents was recorded incompletely, too.

From above, it could be seen that the missing information have had an effect on the comprehensive analysis of the results. Therefore, it is necessary to emphasize the importance of the thorough documentation and make each dental personnel to do a comprehensive understanding, learning and mastering the treatment and prevention on the accidental aspiration and ingestion.

On the one hand, the proposed treatment algorithm is critical for the management of the complications which could be summarized from the literatures.

Firstly, when accidental event occurs, it is essential that clinicians and their staff remain calm and composed. The patient must be reassured and carefully evaluated $[15,16,52]$.

Secondly, thorough clinical and radiological evaluations are required [16]. Early location of an aspirated or ingested foreign body facilitates appropriate and timely treatment management and referral [37]. In cases of aspiration, both posterior-anterior and lateral X-ray films should be taken to confirm the location of foreign objects in the respiratory tract [19]. If the objects (e.g. impression materials or resins) are made of substances that 
lack of radiopacity, diagnostic bronchoscopy or computed tomography is necessary for their localization.

Thirdly, a prompt decision must be made whether to actively remove the object or to let it pass naturally. The subsequently appropriate actions must be taken to prevent potentially serious complications, and may ultimately save the patient's live $[15,16]$.

When the object is located in the oral cavity, finger sweeps is the simplest way. When the object is impacted in the airway, noninvasive procedures for managing airway obstruction include back blows in infants, the Heimlich maneuver, abdominal or chest thrusts in pregnant or obese patients [53].

Once aspirated object is confirmed, urgent management with a flexible or hard fiber optic bronchoscope should be performed $[54,55]$, otherwise it can obstruct the airway [41] or cause pneumonia or a pulmonary abscess [11]. This technique has a success rate of $99 \%$, with a failure rate of 2.4 to $5 \%$ [10]. And the failed cases require surgical intervention of lobectomy.

If an object is swallowed and impacted in the esophagus, prompt removal is required because the esophagus lies in close proximity with the thoracic great vessels, the pericardium, the pleura and the tracheo-bronchial passages [56-58]. If the object goes into the stomach, there is a greater than $90 \%$ chance, especially for some small (less than $2 \mathrm{~cm}$ ), blunt objects, that it will pass through the gastrointestinal tract as a result of peristaltic movement without complications [30, 57-59]. Conservative management should include radiographic surveillance and periodic stool inspection [52]. However, sharp, pointed objects are associated with a higher risk of perforation. The perforation is most likely to take place in the esophagus, the pylorus, the duodenum, the duodenojejunal flexure and the ileocaecal region [60]. Thus, early endoscopic removal should be undertaken [55]. If patients develop symptoms of pain, nausea, vomiting, tenderness or abdominal guarding, perforation should be suspected, and if objects remain lodged longer than 2 weeks, surgical intervention is required $[17,59]$.

Fourthly, the patient should be observed until the object is removed or expelled [21]. A post-operative radiograph should be taken to confirm that the aspirated or ingested instrument has been excreted or removed [52].

Fifthly, thorough documentation of the accident is required as discussed above. Further documentation may include notation of initial and follow-up medical care, clinical experience of the involving assistant or nurse, copies of radiographic reports confirming the diagnosis and notation of removal/expulsion of the objects [21].

On the other hand, prevention through precautionary methods is the most appropriate method to minimize the occurrences of aspiration of dental instruments.
Firstly, every dental personnel should consider the possibility of such emergencies in its standard operating procedures and be well prepared for them [42]. One must be educated and trained regularly to recognize emergencies and how to prevent and minimize adverse events in the work environment $[61,62]$. Individual responsibilities must be delegated to offset any confusion in the event of an emergency so as to organize smooth support and cooperative procedures that can be implemented promptly if accidental ingestion or aspiration occurs [9]. To have available the name, address, and telephone number of an endoscopist and a hospital where full service is available is also necessary.

Secondly, patient's thorough medical and dental history should be reviewed [50]. Special considerations should be associated with those patient populations at high risk, and schedule short appointments to them during the morning are most effective [19].

Thirdly, patients should have enough pre-operation educattion. The dental stuff must ensure complete cooperation and active involvement of patients and their accompany [61].

Fourthly, all the instruments should be periodically check and carefully examined before use for signs of wear or work fatigue and replace those that warrant replacement $[10,11,21,42]$. For example, burs should be fully seated into the handpiece and locked into position [36]. Dental mirrors should be screwed in tightly before being inserted in the mouth [1] Broken burs and instruments should be retrieved and matched up with retained fragments to ensure that all pieces have been recovered [10].

Finally, standard operating procedures with precautions must be taken during any practices. These precautions include appropriate anesthesia and treatment selection, proper body and head positioning, adequate lighting and four-handed dentistry with an attentive assistant and high-speed evacuation, routinely use of a rubber dam and a properly fitting clamp [10, 21], using a $4 \times 4$ inch gauze as a protective barrier in the oral cavity distal to the working area $[1,13,15,16]$, tethering small instrument, cast post, core and crown with a ligature to improve the gripping and reduce the possibility of falling from the hands [13, 63-67].

Of course, there were some limitations in the study. For example, articles in languages other than English were not included in the study. Articles published with only abstract or few details were also not included. These limitations may result in a slight bias in statistical analysis. In addition, some meaningful features were not analyzed. For example, the qualification of the dentists or doctors undergoing the procedure was not analyzed since they were recorded only in a few articles. 


\section{Conclusions}

Although aspiration and ingestion of foreign objects are rare and risky complication during dental procedure, thorough documentation of the accidental aspiration and ingestion of foreign objects during dental procedure is necessary so as to provide enough information for the treatment and prevention.

\section{Acknowledgements}

Not applicable

\section{Funding}

No funding.

\section{Availability of data and materials}

The data supporting the conclusions of this article are included within the article.

\section{Authors' contributions}

$\mathrm{RH}$ and $\mathrm{HZ}$ carried out the studies and drafted the manuscript. YD, XY and GX made the literature search and helped to draft the manuscript. PX, CS, SJ and YM participated in the design of the study and performed the statistical analysis. $\mathrm{RH}$ and $\mathrm{KH}$ conceived of the study and make the critical revision. All authors read and approved the final manuscript.

\section{Competing interests}

The authors declare that they have no competing interests.

\section{Ethics approval and consent to participate}

All the experiments were approved by the Hospital Ethical Committee of the Fourth Military Medical University.

\section{Author details}

${ }^{1}$ State Key Laboratory of Military Stomatology \& National Clinical Research Center for Oral Diseases \& Shaanxi Clinical Research Center for Oral Diseases, Department of Oral Surgery, School of Stomatology, the Fourth Military Medical University, Xi'an City, Shaanxi Province 710032, China. ${ }^{2}$ Department of Stomatology, Research Institute of Surgery \& Daping Hospital, The Third Military Medical University, Chongqing City 400042, China.

Received: 12 January 2016 Accepted: 12 July 2016

Published online: 22 July 2016

\section{References}

1. Pull Ter Gunne L, Wismeijer D. Accidental ingestion of an untethered instrument during implant surgery. Int J Prosthodont. 2014;27(3):277-8.

2. Bernal-Sprekelsen $M$, Hildmann $H$. Ingestion and aspiration of foreign bodies. Anesth Pain Control Dent. 1992;1(1):42-5.

3. Parolia A, Kamath M, Kundubala M, Manuel TS, Mohan M. Management of foreign body aspiration or ingestion in dentistry. Kathmandu Univ Med J (KUMJ). 2009;7:165-71.

4. Worthington P. Ingested foreign body associated with oral implant treatment: report of a case. Int J Oral Maxillofac Implants. 1996;11(5):679-81.

5. Ireland AJ. Management of inhaled and swallowed foreign bodies. Dent Update. 2005:32:83-6. 89.

6. Grossman LI. Prevention in endodontic practice. J Am Dent Assoc. 1971:82(2):395-6.

7. Susini G, Pommel L, Camps J. Accidental ingestion and aspiration of root canal instruments and other dental foreign bodies in a French population. Int Endod J. 2007:40(8):585-9.

8. Hisanaga R, Hagita K, Nojima K, Katakura A, Morinaga K, Ichinohe T, Konomi R, Takahashi T, Takano N, Inoue T. Survey of accidental ingestion and aspiration at Tokyo Dental College Chiba Hospital. Bull Tokyo Dent Coll. 2010;51:95-101.

9. Obinata K, Satoh T, Towfik AM, Nakamura M. An investigation of accidental ingestion during dental procedures. J Oral Sci. 2011;53(4):495-500.

10. Fields Jr RT, Schow SR. Aspiration and ingestion of foreign bodies in oral and maxillofacial surgery: a review of literature and report of five cases. Int J Oral Maxillofac Surg. 1998;56:1091-8.
11. Abusamaan M, Giannobile W, Jhawar P, Gunaratnam NT. Swallowed and aspirated dental prostheses and instruments in clinical dental practice: a report of five cases and a proposed management algorithm. J Am Dent Assoc. 2014;145(5):459-63.

12. Black RE, Johnson DG, Matlak ME. Bronchoscopic removal of aspirated foreign bodies in children. J Pediatr Surg. 1994:29:682e684.

13. Tiwana KK, Morton T, Tiwana PS. Aspiration and ingestion in dental practice: A 10-year institutional review. J Am Dent Assoc. 2004;135:1287-91.

14. Cossellu G, Farronato G, Carrassi A, Angiero F. Accidental aspiration of foreign bodies in dental practice: clinical management and prevention. Gerodontology. 2013. doi:10.1111/ger.12068.

15. Mahesh R, Prasad V, Menon PA. A case of accidental aspiration of an endodontic instrument by a child treated under conscious sedation. Eur J Dent. 2013;7(2):225-8. doi:10.4103/1305-7456.110191.

16. Mohan R, Rao S, Benjamin M, Bhagavan RK. Accidental ingestion of a barbed wire broach and its endoscopic retrieval:prevention better than cure. Indian J Dent Res. 2011;22(6):839-42. doi:10.4103/0970-9290.94681.

17. Bhatnagar S, Das UM, Chandan GD, Prashanth ST, Gowda L, Shiggaon N. Foreign body ingestion in dental practice. J Indian Soc Pedod Prev Dent. 2011;29(4):336-8. doi:10.4103/0970-4388.86387.

18. Venkataraghavan $K$, Anantharaj A, Praveen P, Rani SP, Krishnan BM. Accidental ingestion of foreign object: Systematic review, recommendations and report of a case. Saudi Dent J. 2011;23(4):177-81. doi:10.1016/j.sdentj. 2010.10.007. Epub 2010 Nov 9.

19. Deliberador TM, Marengo G, Scaratti R, Giovanini AF, Zielak JC, Baratto FF. Accidental aspiration in a patient with Parkinson's disease during implantsupported prosthesis construction: a case report. Spec Care Dentist. 2011; 31(5):156-61. doi:10.1111/j.1754-4505.2011.00202.x.

20. Sopeña B, García-Caballero L, Diz P, De la Fuente J, Fernández A, Díaz JA. Unsuspected foreign body aspiration. Quintessence Int. 2003;34(10):779-81.

21. Hodges ED, Durham TM, Stanley RT. Management of aspiration and swallowing incidents: a review of the literature and report of case. ASDC Dent Child. 1992;59(6):413-9.

22. Goldberg NB, Goldbert AF, Rubenstein L. Instrument aspiration. Quintessence Int. 1989;20(8):603-5.

23. Alexander RE, Delhom JJ. Rubber dam clamp ingestion, an operative risk: report of case. J Am Dent Assoc. 1971;82(6):1387-9.

24. Saraf HP, Nikhade PP, Chandak MG. Accidental ingestion of endodontic file: a case report. Case Rep Dent. 2012;2012:278134. doi:10.1155/2012/278134. Epub 2012 Apr 17

25. Oncel M, Apiliogullari B, Cobankara FK, Apiliogullari s. Accidental swallowing of the head of a dental mirror: Report of a rare case. J Dent Sci. 2012:7(2):199-202.

26. Zitzmann NU, Elsasser S, Fried R, Marinello CP. Foreign body ingestion and aspiration. Oral Surg Oral Med Oral Pathol Oral Radiol Endod. 1999;88(6):657-60

27. Govila CP. Accidental swallowing of an endodontic instrument. A report of two cases. Oral Surg Oral Med Oral Pathol. 1979;48(3):269-71.

28. Cameron SM, Whitlock WL, Tabor MS. Foreign body aspiration in dentistry: a review. J Am Dent Assoc. 1996;127(8):1224-9.

29. Santos Tde S, Antunes AA, Vajgel A, Cavalcanti TB, Nogueira LR, Laureano F. Foreign body ingestion during dental implant procedures. J Craniofac Surg. 2012;23(2):e119-23. doi:10.1097/SCS.0b013e31824cda32.

30. Pingarrón Martín L, Morán Soto MJ, Sánchez Burgos R, Burgueño GM. Bronchial impaction of an implant screwdriver after accidental aspiration: report of a case and revision of the literature. Oral Maxillofac Surg. 2010;14(1):43-7. doi:10.1007/s10006-009-0178-0.

31. Elgazzar RF, Abdelhady Al, Sadakah AA. Aspiration of an impacted lower third molar during its surgical removal under local anaesthesia. Int J Oral Maxillofac Surg. 2007:36(4):362-4. Epub 2006 Nov 15.

32. Dhanrajan P. Swallowing of tonsillar pack in recovery following general anaesthesia. Br J Oral Maxillofac Surg. 2013:51(6):e132-4.

33. Bergermann $M$, Donald PJ, aWengen DF. Screwdriver aspiration: $A$ complication of dental implant placement. Int J Oral Maxillofac Surg. 1992;21(6):339-41

34. Lambrianidis T, Beltes P. Accidental swallowing of endodontic instruments. Endod Dent Traumatol. 1996;12(6):301-4.

35. Mejia JL, Donado JE, Posada A. Accidental swallowing of a dental clamp. J Endod. 1996;22(11):619-20.

36. Israel HA Leban SG. Aspiration of an endodontic instrument. J Endod. 1984;10(9):452-4 
37. Kuo SC, Chen YL. Accidental swallowing of an endodontic file. Int Endod J. 2008;41:617-22.

38. de Souza JG, Schuldt Filho G, Pereira Neto AR, Lyra Jr HF, Bianchini MA, Cardoso AC. Accident in implant dentistry:Involuntary screwdriver ingestion during surgical procedure. A clinical report. J Prosthodont. 2012;21(3):191-3. doi:10.1111/j.1532-849X.2011.00826.x.

39. Ulusoy M, Toksavul S. Preventing aspiration or ingestion of fixed restorations. J Prosthet Dent. 2003;89(2):223-4.

40. Kim A, Ahn KM. Endoscopic removal of an aspirated healing abutment and screwdriver under conscious sedation. Implant Dent. 2014;23(3):250-2. doi:10.1097/ID.0000000000000100.

41. Tripathi $T$, Rai $P$, Singh $H$. Foreign body ingestion of orthodontic origin. Am J Orthod Dentofacial Orthop. 2011;139(2):279-83. doi:10.1016/j. ajodo.2009.04.026

42. Umesan UK, Ahmad W, Balakrishnan P. Laryngeal impaction of an archwire segment after accidental ingestion during orthodontic adjustment. Am J Orthod Dentofacial Orthop. 2012;142(2):264-8. doi:10.1016/j.ajodo.2011.05.025.

43. Lankisch TO, Manns MP, Wedemeyer J. Why men should not iron: unperceived swallowed dental root instrument causes seven years of abdominal pain. Clin Gastroenterol Hepatol. 2008;6(9):xxxii. doi:10.1016/j. cgh.2008.01.018. Epub 2008 Jun 2.

44. Bettschart RW, Bolliger CT. Symptomless aspiration of a dental drill. Respiratio. 2009;78(3):329. Epub 2007 Aug 29.

45. Tu CY, Chen HJ, Chen W, Liu YH, Chen CH. A feasible approach for extraction of dental prostheses from the airway by flexible bronchoscopy in concert with wire loop Snares. Laryngoscope. 2007;117(7):1280-2.

46. Li Voti G, Di Pace MR, Castagnetti M, De Grazia E, Cataliotti F. Needle perforation of the bowel in childhood. J Pediatr Surg. 2004;39(2):231-2.

47. Sankar NS. Accidental ingestion of a dental instrument. J R Soc Med. 1998;91(10):538-9.

48. Ankur Thakral, Subrato Sen, V.P. Singh, N. Ramakrishna, V.B. Mandlik. Aspiration of an endodontic file. Medical J Armed Forces India.2013, In Press, Corrected Proof, Available online 20 November 2013

49. Baghele ON, Baghele MO. Accidental ingestion of BiTine ring and a note on inefficient ring separation forceps. Ther Clin Risk Manag. 2011;7:173-9.

50. Zitzmann NU, Fried R, Elsasser S, Marinello CP. The aspiration and swallowing of foreign bodies. The management of the aspiration or swallowing of foreign bodies during dental treatment. [In French, German.] Schweiz Monatsschr Zahnmed 2000:110:619-32.

51. Whitten BH, Gardiner DL, Jeansonne BG, Lemon RR. Current trends in endodontic treatment: report of a national survey. J Am Dent Assoc. 1996;127:1333-41.

52. Uyemura MC. Foreign body ingestion in children. Am Fam Physician. 2006;73(8):1332

53. Hoekelman RA, Friedman SB, Nelson NM, Seidel HM. Primary Pediatric Care, 2nd ed. CV Mosb Year Book, St. Louis, 1992. 263-263, 1249-1251.

54. Dikensoy O, Usalan C, Filiz A. Foreign body aspiration: clinical utility of flexible bronchoscopy. Postgrad Med J. 2002;78:399-403.

55. Soergel KH, Hogan WJ. Therapeutic endoscopy. Hosp Pract. 1983;18:81-92.

56. Milton TM, Hearing SD, Ireland AJ. Ingested foreign bodies associated with orthodontic treatment: Report of three cases and review of ingestion/ aspiration incident management. Br Dent J. 2001;190:592-6.

57. Samdani T, Singhal T, Balakrishnan S, Hussain A, Grandy-Smith S, El- Hasani S. An apricot story: View through a keyhole. World J Emerg Surg. 2007;2:20.

58. Chung YS, Chung YW, Moon SY, Yoon SM, Kim MJ, Kim KO, et al. Toothpick impaction with sigmoid colon pseudodiverticulum formation successfully treated with colonoscopy. World J Gastroenterol. 2008;14:948-50.

59. Webb WA. Management of foreign bodies of the upper gastrointestinal tract. Gastroenterology. 1988;94:204-16.

60. Allwork JJ, Edwards IR, Welch IM. Ingestion of a quadhelix appliance requiring surgical removal: a case report. J Orthod. 2007;34(3):154-7.

61. Umesan UK, Chua KL, Balakrishnan P. Prevention and management of accidental foreign body ingestion and aspiration in orthodontic practice. Ther Clin Risk Manag. 2012;8:245-52. doi:10.2147/TCRM.S30639.

62. Rohida NS, Bhad WA. Accidental ingestion of a fractured Twin-block appliance. Am J Orthod Dentofacial Orthop. 2011;139(1):123-5.

63. Wilcox CW, Wilwerding TM. Aid for preventing aspiration/ingestion of single crowns. J Prosthet Dent. 1999:81:370-1.
64. American Academy on Pediatrics; American Academy on Pediatric Dentistry Guideline for monitoring and management of pediatric patients during and after sedation for diagnostic and therapeutic procedures. Pediatr Dent 2008-2009:30:143-

65. Al-Rashed MA. A method to prevent aspiration or ingestion of cast post and core restorations. J Prosthet Dent. 2004;91(5):501-2.

66. Nakajima M, Sato Y. A method for preventing aspiration or ingestion of fixed restorations. J Prosthet Dent. 2004;92(3):303.

67. Wilwerding TM. Preventing aspiration or ingestion of single fixed restorations. J Prosthet Dent. 1990;63(4):489.

\section{Submit your next manuscript to BioMed Central and we will help you at every step:}

- We accept pre-submission inquiries

- Our selector tool helps you to find the most relevant journal

- We provide round the clock customer support

- Convenient online submission

- Thorough peer review

- Inclusion in PubMed and all major indexing services

- Maximum visibility for your research

Submit your manuscript at www.biomedcentral.com/submit 